\title{
Myrmecodia platytyrea Methanol Tuber Extract Ameliorates Hyperglycemia In STZ-Induced Diabetic Sprague-Dawley Male Rats
}

\author{
Mizaton Hazizul Hasan*, Hasbullani Zakaria, Ibtisam Abdul Wahab, Thellie Ponto, and Aishah Adam
}

Faculty of Pharmacy, Universiti Teknologi MARA, Selangor Campus, 42300 Bandar Puncak Alam, Selangor, Malaysia.

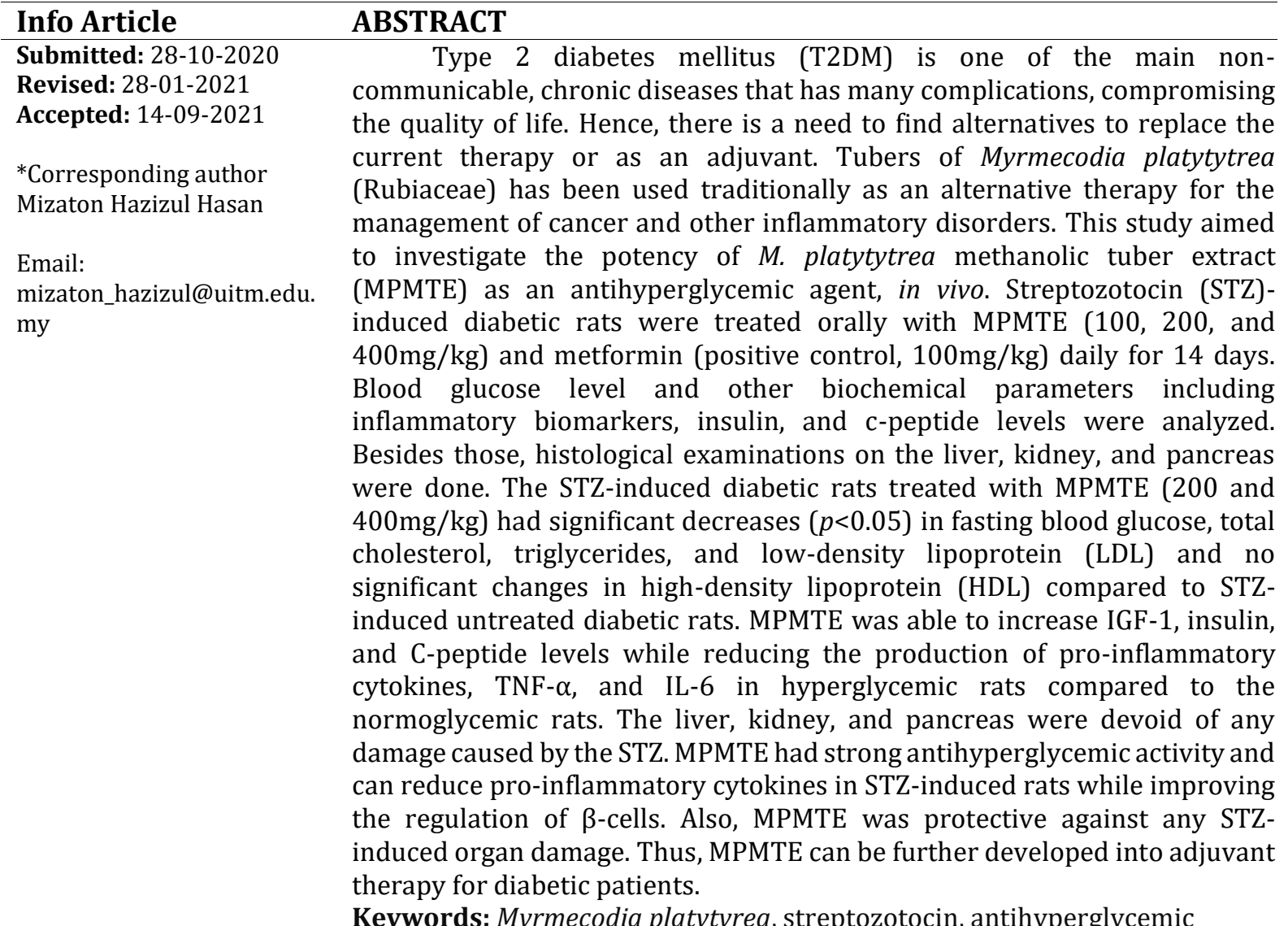

Keywords: Myrmecodia platytyrea, streptozotocin, antihyperglycemic

\section{INTRODUCTION}

The global prevalence of diabetes mellitus has increased dramatically since globalization has led to social effects such as urbanization and lifestyle changes (Fox, et al., 2019; Zimmet et al., 2014). Diabetes, especially type 2 diabetes mellitus (T2DM), is emerging as a potential epidemic in developing countries such as China and India, not only in the developed world (Hu and Jia, 2018; Misra et al., 2019; Shaw, et al., 2010). T2DM used to be an exclusive metabolic syndrome for adults but its prevalence is now increasing among teenagers and even youngsters (Cree-Green, Triolo \& Nadeau, 2013; Pinhas and Zeitler, 2005). In 2019, about 463 million adults (20-79 years) were projected to have diabetes and by 2045 this figure is expected to rise to 700 million, worldwide (International Diabetes Federation, 2020). According to the National Health and Morbidity Survey (NHMS) in 2019 by the Ministry of Health (MOH), the prevalence rate of diabetes in adults has increased in Malaysia from 13.4 percent in 2015 to 18.3 percent in 2019 , with diabetes defined as having sugar levels $7.0 \mathrm{mmol} / \mathrm{L}$ or above (Institute for Public Health, 2020). Although there are varieties of pharmacological agents to control blood glucose levels such as insulins, sulfonylureas, biguanides, thiazolidinediones, and DPP IV, which is the most recent one, diabetes remains a social and economic burden. Lifestyle changes involving exercise and 
dietary intervention is essential to achieve management goals cost-effectively with minimum complications and maximum quality of life. Pharmacological management of diabetes is often associated with undesirable side effects and the inability of human nature to comply with the regimen. Thus, dietary intervention is the most powerful tool to challenge and keep the disease at bay.

Herbs and spices have been shown to have medicinal properties and many have demonstrated strong pharmacological activities (Liu et al., 2017; Vázquez-Fresno et al., 2019). In controlled clinical trials on herbal medicines especially for the management of diabetes, significantly positive clinical outcomes had been reported (Shi et al., 2019). It was reported that only $12 \%$ out of 1000 plants available in the market had scientific evidence of their efficacies i.e. only 356 plants have been tested for pharmacological effects and therapeutic applications (Cravotto et al., 2010). There were also reports of positive clinical outcomes in response to the use of nutraceuticals containing Traditional Chinese Medicine (TCM) in the management of diabetes (Shi et al., 2019). However, both the safety and efficacy of these nutraceuticals are precedent to ensure optimum therapeutic value for the management of chronic illnesses.

On that note, Myrmecodia sp. is an epiphytic plant that has a structure similar to an anthill tuber that houses ants (Lok and Tan, 2009). Myrmecodia platytyrea (Rubiaceae) has been used as a medicine to treat tuberculosis, diarrhea, hemorrhoids, and ulcers. This plant has also been used in cancer treatment, hyperuricemia, and coronary heart disease.

The decoction of $M$. platytyrea tuber has been used for medicinal purposes. Folklore claims the efficacy of this plant in treating many chronic diseases such as cancer, arthritis, coronary heart diseases, and many inflammation-related diseases. However, there was no scientific evidence to support these anecdotes. The current study in our laboratory has shown the effectiveness of the aqueous extract of $M$. platytyrea tuber in inhibiting the proliferation of hepatocellular carcinoma cells without affecting the normal cells, suggesting high selectivity. The extract also possessed potent antiinflammatory activities (Hasan et al., 2018). Furthermore, antioxidants, polyphenols, and stigmasterol were detected in the $M$. platytyrea tuber extracts via a rapid and simple HPLTC method. The extracts also exhibited significant $\alpha$-amylase inhibitory activities (Aganotovic-Kustrin et al., 2017, 2018).

Previous studies have demonstrated that the elevation of inflammatory cytokine levels plays a role in the pathogenesis of T2DM (Calle and Fernandez, 2012). Since M. platytyrea tuber has shown potent anti-inflammatory properties, there are possibilities for this plant to be used in the prevention or management of diabetes. Therefore, this research was aimed to elucidate the possible hypoglycemic effect of $M$. platytyrea, in vivo.

\section{MATERIAL AN D METHODS}

Chemicals that were used in this experiment were of analytical grade and purchased from Sigma-Aldrich Co. (Steinheim, Germany), Merck, and other registered suppliers. All reagent kits were purchased from registered suppliers.

\section{Plant collection}

M. platytyrea tubers were collected from Sulawesi, Indonesia, and had been authenticated by Prof. Dr. Eko Baroto Walujo, from Herbarium Bogoriense, Research Centre for Biology, Indonesian Institute of Sciences, Bogor, Indonesia with identification numbers, B01647929 and B00009642.

\section{Experimental animals}

A chemically induced diabetic rat model was used in this study, which is a simple and relatively cheap model of diabetes in rodents. This diabetic rat was obtained by the destruction of endogenous $\beta$-cells which leads to a decrease in insulin production, hyperglycemia, and weight loss. Sprague-Dawley (SD) male rats aged 10 weeks, weighed between 250-300 g were supplied by the Laboratory of Animal Facility and Management (LAFAM), UiTM Puncak Alam, Selangor. The temperature of the experimental room was set to $22^{\circ} \mathrm{C}\left( \pm 3^{\circ} \mathrm{C}\right)$ and relative humidity was set to at least $30 \%$. The rats were kept in a $12 \mathrm{~h}$ light-dark cycle and were given a standard laboratory diet with an unlimited supply of drinking water. The use of animals in the in vivo studies had been approved by UiTM Animal Ethics Committee (UiTM CARE: 102/2015). All animals were housed in individually ventilated cages (Modular Animal Caging Systems, Alternative Design Manufacturing \& Supply, Inc., Siloam Springs, Arkansas, U.S.A) of cage dimension $72 \mathrm{~cm} \mathrm{~W} \times 36 \mathrm{~cm} \mathrm{D} \mathrm{x} 44 \mathrm{~cm} \mathrm{H}$. All animals were provided laboratory standard, pelleted rodent diet (Gold Coin Feed Mills, Penang, Malaysia) and filtered tap water, ad libitum. 


\section{Preparation of M. platytyrea crude extracts}

The dried tubers of $M$. platytyrea were ground into powder form. The powder was then boiled in distilled water (1:9) for $15 \mathrm{~min}$ and filtered using filter paper (Whatman No. 1). The solvent of the filtrate was eliminated by using a rotary evaporator (Heidolph, Germany) under reduced pressure at $100 \mathrm{mbar}, 40^{\circ} \mathrm{C}$. The concentrated filtrate was stored at $-80^{\circ} \mathrm{C}$ for three days and freeze-dried (AAPPTec, USA) to obtain the dried powder of the aqueous extract. The extract was kept at $20^{\circ} \mathrm{C}$ until further use.

\section{Animal treatment}

STZ ( $45 \mathrm{mg} / \mathrm{kg} ;$ i.p.) was injected into the rats based on body weight $(0.1 \mathrm{~mL} / 100 \mathrm{~g}$ b.w. $)$ on day 1 except for one group (normal, non-induced group) which were injected (i.p.) with $0.1 \mathrm{M}$ citrate buffer ( $\mathrm{pH} 4.5$ ). After 5 days, blood from the fasting rat was taken from the tail vein to measure the blood glucose level. Rats with fasting blood glucose level of $>8.1 \mathrm{mmol} / \mathrm{L}$ were considered diabetic (Oyedemi et al., 2012) and were divided randomly into 6 groups ( 6 rats per group): normal non-STZinduced, normal STZ-induced, positive control, and three groups for treatment $(100,200$, and 400 $\mathrm{mg} / \mathrm{kg}$ of MPMTE). Rats were given normal saline orally (control group and control non-induced group), metformin (100 mg/kg, positive control), and MPMTE for the next 14 days.

The glucose level of the fasting rats was measured weekly. At the end of the study, the rats were anesthetized with pentobarbital, and blood was drawn using cardiac puncture to collect data on fasting blood glucose level, insulin level, and lipid profile. The liver, kidney, stomach, and pancreas were excised for histological examinations.

\section{Measurement of glucose level}

Rats fasted overnight and blood from the tail vein was drawn to estimate for fasting blood glucose using a glucometer (from Accu-Chek). The blood glucose level was measured on days 0,7 , and 14 after treatment.

\section{Measurement of lipid profile}

The serum was separated by centrifugation at 4000rpm for $15 \mathrm{~min}$. Triglycerides, cholesterol, LDL, and HDL were measured using an automated clinical chemistry analyzer (I-Lab 300 plus, U.K) by adopting procedures described in the biochemical kits (Instrumentation Laboratory, Milano Italy).

\section{Measurement of Inflammatory Biomarkers, Insulin and $\mathrm{C}$-peptide}

Levels of Interleukin-6 (IL-6), insulin-like growth factor 1 (IGF-1), Tumor Necrosis Factor- $\alpha$ (TNF- $\alpha$ ), insulin, and c-peptide were measured in rat serum by sandwich ELISA (Elabscience, China) according to the instructions of the manufacturer.

\section{Histological Analysis}

The pancreas, lung, kidney, and liver from the respective treatment groups were harvested and fixed in 10\% neutral buffered formalin for 72 hours. The tissues were then processed for hematoxylin \& eosin (H\&E) staining. All prepared slides were observed and analyzed double-blind by a trained pathologist under a light microscope (Leica, Germany).

\section{Statistical Analysis}

All the data were expressed as mean \pm SEM $(n=6)$. Statistical differences between the treatments and the controls were tested by twoway analysis of variance (ANOVA) followed by Duncan post hoc test of intergroup comparison. A difference in the mean values of $\mathrm{p}<0.05$ was considered statistically significant.

\section{RESULTS AND DISCUSSION \\ Effect of MPMTE on Glucose Level}

The initial reading of glucose levels taken on day 1 , on hyperglycemic rats for the untreated group, treatment groups of MPMTE (100, 200 and $400 \mathrm{mg} / \mathrm{kg}$; p.o.) and metformin were higher $(9.9 \pm 0.4,9.6 \pm 0.3,9.6 \pm 0.1,9.6 \pm 0.1$ and $9.5 \pm 0.1$ mmol/L, respectively) compared to the normoglycemic rats $(5.2 \pm 0.4 \mathrm{mmol} / \mathrm{L})$. At days 7 and 14, hyperglycemic rats treated with MPMTE $(200$ and $400 \mathrm{mg} / \mathrm{kg})$ and metformin demonstrated a significant $(p<0.05)$ decline in fasting glucose levels compared to the untreated hyperglycemic rats (Figure 1). The oral capacity of MPMTE to decrease the elevated blood sugar to a normal level is an essential trigger for the liver to revert to its normal homeostasis during experimental diabetes. This may be due to the presence of bioactive compounds such as polyphenols and stigmasterol in the extract that can regulate glucose metabolism (AganotovicKustrin etal., 2017,2018). 


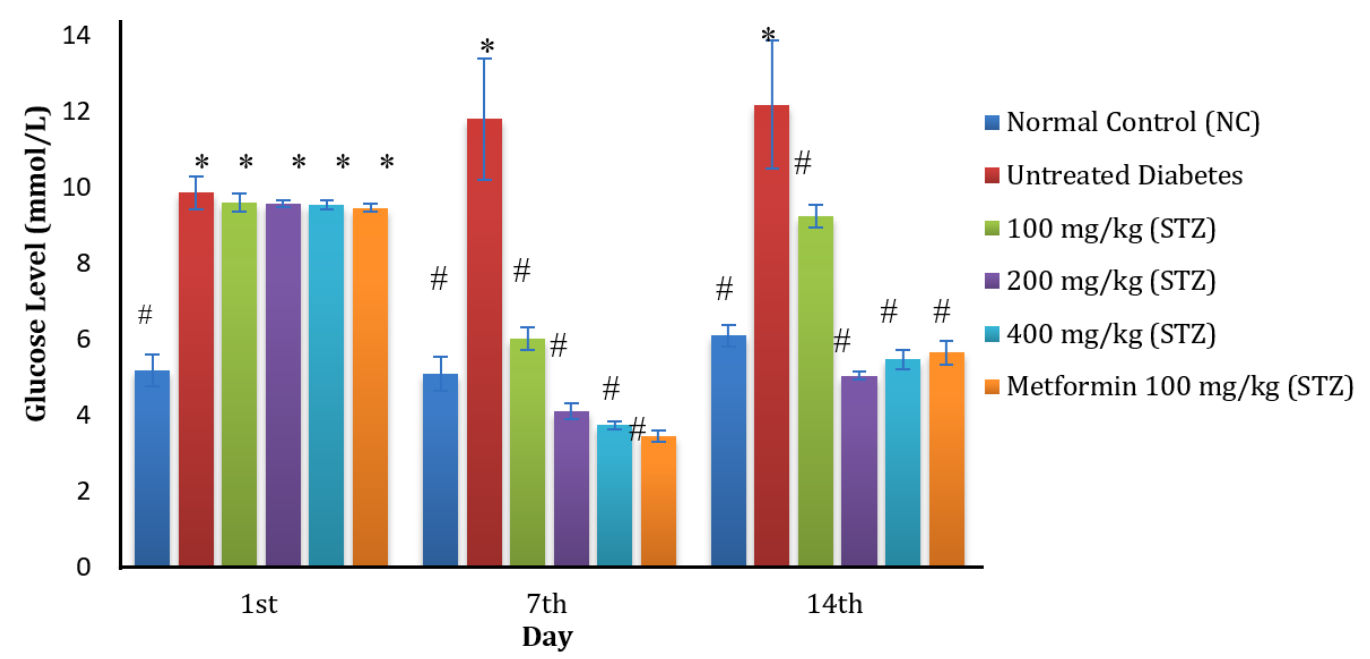

Figure 1 Effect of MPMTE on glucose level (mmol/L). Glucose levels of normal rats and STZ-induced diabetic rats were measured per week. The values are mean \pm SEM (n=6/group).
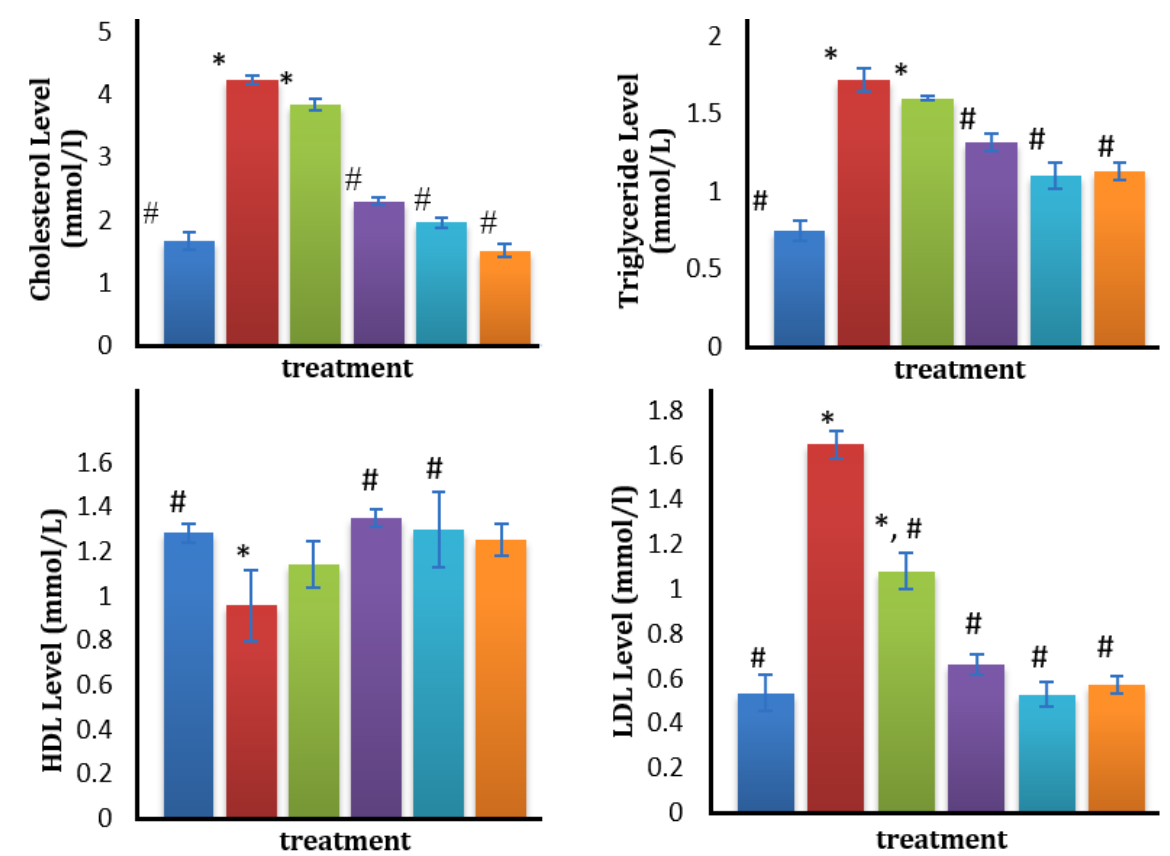

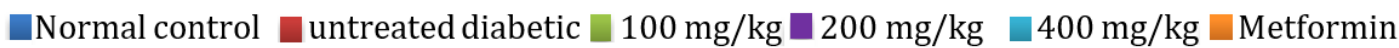

Figure 2 Effect of MPMTE on (a) cholesterol, (b) triglycerides, (c) HDL, and (d) LDL levels. The lipid profile of normal rats and STZ-induced diabetic rats were measured at the end of the study. The values are mean \pm SEM ( $n=6 /$ group). *vs normal control; \#vs untreated diabetes $(p<0.05$, One Way ANOVA followed by post hoc Duncan test).

The possible mechanism for hypoglycemic action by MPMTE in diabetic rats may be through the improvement of the glycemic control mechanism and insulin secretion from remnant pancreatic beta cells or regenerated beta cells in the diabetic rats (Gandhi and Sasikumar, 2012; Punitha and Manohara, 2006).

\section{Effect of Various Doses of MPMTE on Lipid Profile}

Hyperglycemic rats treated with MPMTE (200 and $400 \mathrm{mg} / \mathrm{kg}$ ) and metformin demonstrated a significant decrease $(p<0.05)$ in cholesterol and triglyceride levels compared to the untreated hyperglycemic rats (Figure $2 \mathrm{a}$ and $2 \mathrm{~b}$ ). 
However, no significant difference in HDL levels was observed in all treated hyperglycemic rats compared to the untreated hyperglycemic rats (Figure 2c). Hyperglycemic rats that were given MPMTE $(100,200$, and $400 \mathrm{mg} / \mathrm{kg})$ and metformin showed a significant decrease $(p<0.05)$ in LDL levels compared to normoglycemic rats (Figure 2d). Administration of STZ caused lipid abnormalities, due to insulin resistance and hyperglycemia (Samatha et al., 2012). Treatment with MPMTE produced a significant decrease in triglycerides, total cholesterol, and LDL cholesterol levels in diabetic rats. However, MPMTE was not able to improve the HDL level. Some studies demonstrated treatment with insulin did not restore the HDL concentrations to normal (Hollenbek et al., 1986). In diabetes, HDL decreases due to the non-enzymatic glycosylation of HDL that accelerates its catabolism where glycated HDL clearance is accelerated from the circulation (Witztum et al., 1982). However, in our study, diabetic rats did not show any increment in HDL level as compared to control. Hence, supplementation of MPMTE neither elevates nor normalizes the HDL level although there was an excellent glycemic control observed. This remarkable glycemic control may be contributed by polyphenols and plant sterols in the extract that could improve the lipid profile and regulate glucose metabolism. Furthermore, studies have shown that these compounds, which were isolated from the tuber of M. platytyrea, alter lipid metabolism (Dai et al., 2015; Feng et al., 2018).

\section{Effects of MPMTE on Inflammatory Biomarkers, Insulin, and C-peptide}

All treated rats $(100,200$, and $400 \mathrm{mg} / \mathrm{kg}$ of MPMTE; p.o.) and positive control $(100 \mathrm{mg} / \mathrm{kg}$ metformin; p.o.) showed significant differences in IGF-1 levels, in comparison to the normoglycemic rats. The highest level of IGF-1 was observed in rats treated with $400 \mathrm{mg} / \mathrm{kg}$ of MPMTE $(125.1 \pm 3.6 \mathrm{pg} / \mathrm{mL})$, compared to untreated hyperglycemic rats $(52.5 \pm 9.6 \mathrm{pg} / \mathrm{mL})$ (Figure 3a). An increment in insulin levels was observed in all the treatment groups of MPMTE and metformin compared to untreated hyperglycemic rats (Figure $3 b)$. Significant reduction $(\mathrm{p}<0.05)$ in TNF- $\alpha$ and IL6 levels were observed in all the treatment groups of MPMTE and metformin compared to the untreated hyperglycemic rats (Figure $4 \mathrm{a}$ and $4 \mathrm{~b}$ ). MPMTE ( $400 \mathrm{mg} / \mathrm{kg}$; p.o.) and metformin were able to significantly increase $(\mathrm{p}<0.05)$ the $\mathrm{C}$-peptide levels compared to those in untreated hyperglycemic rats (Figure 3c).

Our results also indicated MPMTE was able to increase IGF-1, insulin, and C-peptide levels while reducing the production of pro-inflammatory cytokines, TNF- $\alpha$, and IL-6 in hyperglycemic rats. Both insulin and IGF-1 are important in the regulation of $\beta$-cell growth and function (Kulkarni, 2005). Thus, therapeutic improvement of insulin and IGF-1 signaling in $\beta$ cells might protect against T2DM (Ueki et al., 2006). Glucose involves as a regulatory molecule for inducing $\beta$ cells to stimulate the secretion of insulin and IGF-1. It is known that this glucose-dependent IGF-1 activation system enhances the glycolytic pathway for cell proliferation (Hugl et al., 1998). Thus, the increase of both IGF-1 and insulin levels proved that MPMTE was able to regenerate $\beta$-cells and enhance insulin and IGF-1 secretion. C-peptide is secreted from pancreatic $\beta$-cells at an equimolar ratio to insulin and exhibits endogenous insulin secretion more accurately than insulin (Saisho, 2016). Therefore, C-peptide is used as a marker of $\beta$-cell function. The improvement of C-peptide levels in MPMTE-treated hyperglycemic rats suggested that MPMTE managed to improve $\beta$-cell function, which enhanced insulin secretion and increased glucose uptake into muscle, liver, and adipose tissue.

The first factor at the crossroads of inflammation and metabolic disease was TNF- $\alpha$ and excess production of TNF- $\alpha$ in tissue is due to insulin resistance (Wellen and Hotamisligil, 2005). Expressions of IL-1 $\beta$, IL- 6 , and TNF- $\alpha$ were reported in diabetic rats and the increased production of IL- 6 and IFN- $\gamma$ by STZ-induced diabetic rats was identified as autoimmune diabetes (Ehses et al., 2009; Ishihara and Hirano, 2002). Hence, the reduction of TNF- $\alpha$ and IL-6 in the MPMTE-treated hyperglycemic rats indicated that MPMTE may be a potent agent against diabetes-related inflammatory injury via inhibition of inflammatory cytokine production. MPMTE managed to ameliorate insulin resistance and impede pro-inflammatory cytokines due to the presence of bioactive compounds such as polyphenols, plant sterols, and iridoid lactone in the tuber extract (Aganotovic-Kustrin et al., 2017, 2018; Mohamad Haris et al., 2016). These compounds isolated from the tubers of $M$. platytyrea have been reported to have potent antiinflammatory properties (Viljoen, Mncwangi \& Vermaak, 2012). 

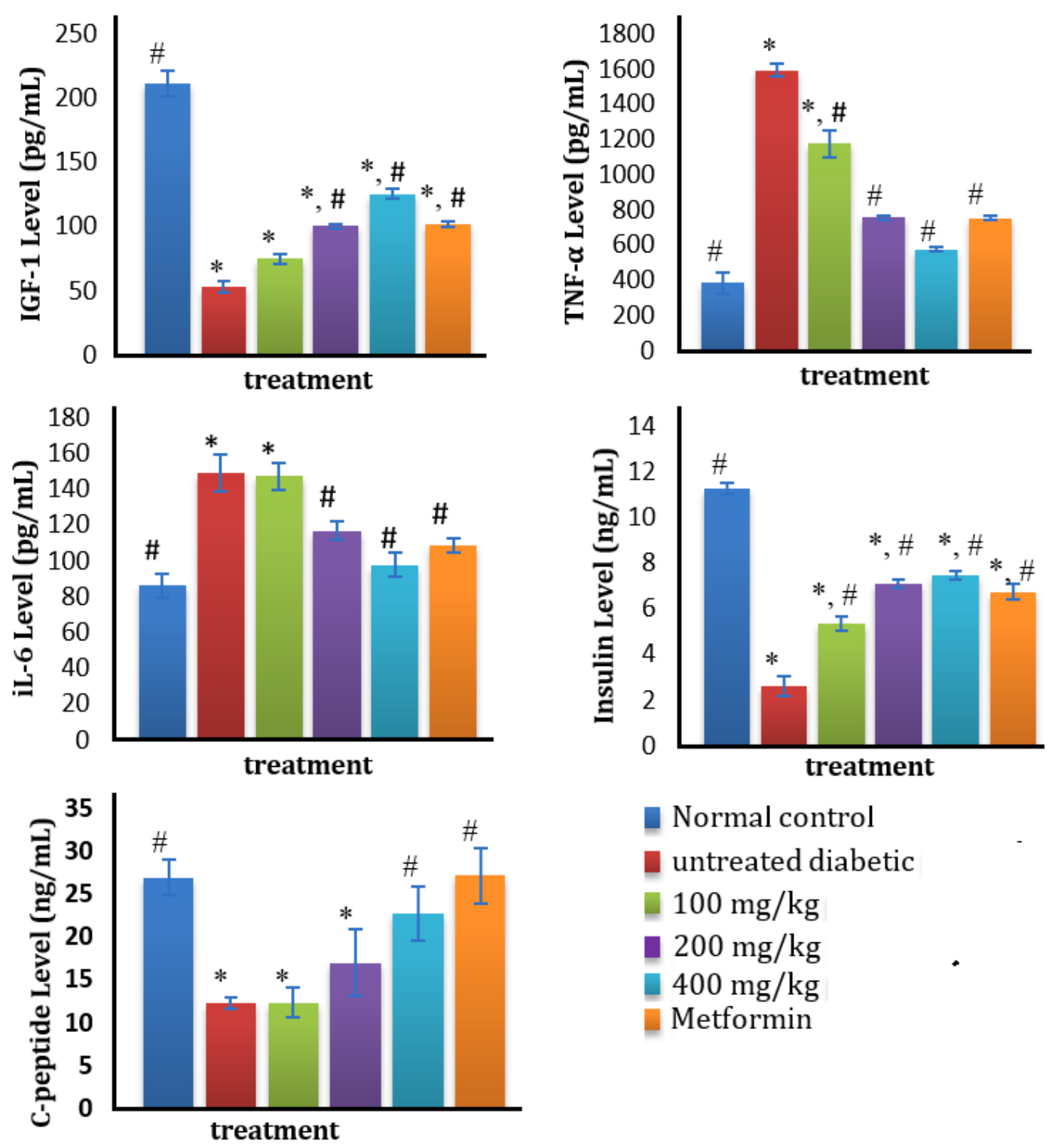

Figure 3 Effect of MPMTE on (a) IGF-1, (b) TNF- $\alpha$, (c) IL-6, (d) insulin, and (e) C-peptide levels. Inflammatory biomarkers, insulin and C-peptide levels of normal rats and STZ-induced diabetic rats were measured at the end of the study. The values are mean \pm SEM ( $n=6 /$ group).

*vs normal control; "vs untreated diabetes ( $p<0.05$, One Way ANOVA followed by post hoc Duncan test).

\section{Effect of MPMTE on Pancreas, Kidney, and Liver}

Histological evaluation was conducted on the pancreas (Fig. 4), kidney (Fig. 5), and liver (Fig. 6). The analysis revealed that STZ caused extensive damage in pancreatic $\beta$-cells, such as a reduction in islet cells' numbers, cell necrosis, and death. The exocrine tissue of the pancreas remained relatively affected after the STZ treatment. Administration of MPMTE to STZ-induced hyperglycemic rats partially restored the pancreatic islets. This finding supports the increase in insulin, C-peptide, and IGF1 levels found in the serum of MPMTE-treated diabetic rats. Insulin, C-peptide, and IGF-1 are important in the regulation of $\beta$-cell growth and function. These restorative effects may be due to the high contents of flavonoids, polyphenols, and condensed tannins, which were involved in the curative process of free radical-mediated diseases, including diabetes and its complications (Mohammad et al., 2016). 




Figure 4. Histopathological changes in the pancreas of normal and experimental rats. All the sections are in H\&E 40X. (a) Control rat pancreas. Normal pancreas with islet cell surrounded by acini (yellow arrow). (b) Diabetic rat pancreas shows atrophic acini with fatty infiltration (yellow arrow). (c) Diabetic $+100 \mathrm{mg} / \mathrm{kg}$ of MPMTE (mild expansion and absence of dilations) (yellow arrow). (d) Diabetic $+200 \mathrm{mg} / \mathrm{kg}$ of MPMTE (moderate expansion of pancreatic islets) (yellow arrow). (e) Diabetic $+400 \mathrm{mg} / \mathrm{kg}$ of MPMTE (moderate expansion of islet cells with few atrophic acini) (yellow arrow). (f) Diabetic $+100 \mathrm{mg} / \mathrm{kg}$ of Metformin (atrophic acini with fatty infiltration (yellow arrow).
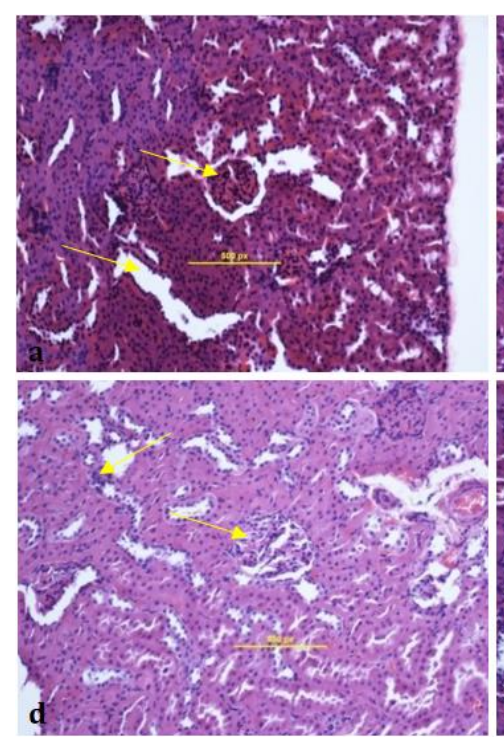
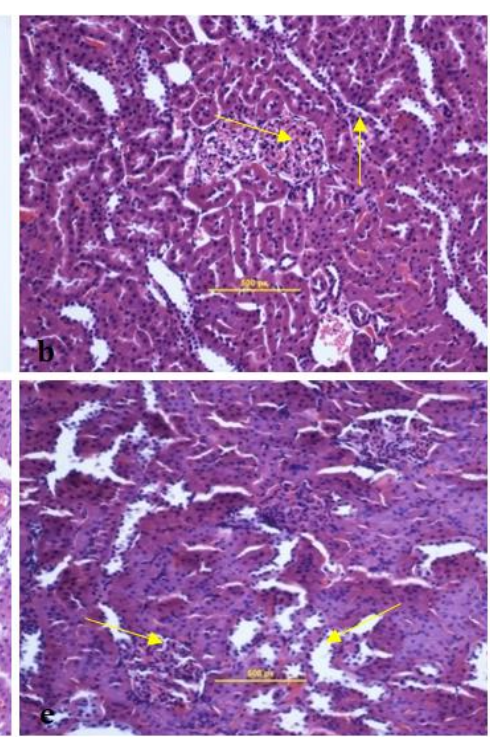
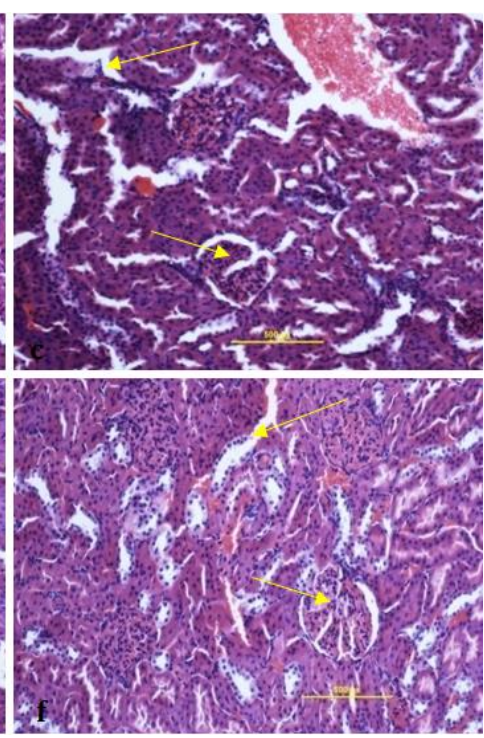

Figure 5 Histopathological changes in the kidney of normal and experimental rats. All the sections are in H\&E 40X. (a) Control rat (kidney shows normal glomeruli and tubules) (yellow arrow). (b) Diabetic rat kidney. Glomeruli with mesangiocapillary proliferation (yellow arrow). (c) Diabetic rat $+100 \mathrm{mg} / \mathrm{kg}$ of MPMTE. Glomeruli with mesangiocapillary proliferation (yellow arrow). (d) Diabetic rat $+200 \mathrm{mg} / \mathrm{kg}$ of MPMTE (Tubules shows proteinuria and glomerular damage) (yellow arrow). (e) Diabetic $+400 \mathrm{mg} / \mathrm{kg}$ of MPMTE (shows glomeruli and tubules without proteinuria and hemorrhage) (yellow arrow). (f) Diabetic + $100 \mathrm{mg} / \mathrm{kg}$ of Metformin (shows glomeruli and tubules without proteinuria and hemorrhage) (yellow arrow). 

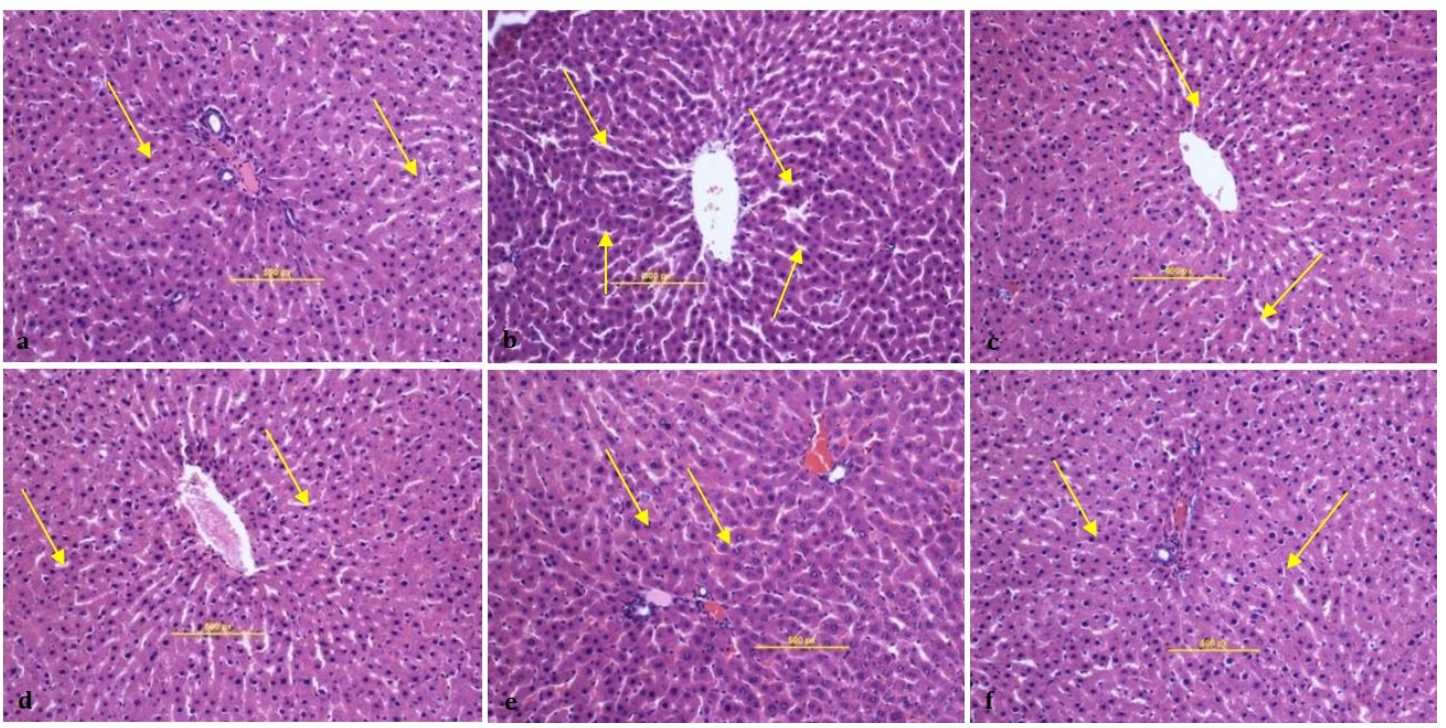

Figure 6 Histopathological changes in the liver of normal and experimental rats. All the sections are in H\&E 40X. (a) Control rat Liver shows portal triad surrounded by hepatocytes (yellow arrow). (b) Diabetic rat (showing the periportal fatty infiltration) (yellow arrow). (c) Diabetic rat $+100 \mathrm{mg} / \mathrm{kg}$ of MPMTE (showing the periportal fatty infiltration) (yellow arrow). (d) Diabetic rat $+200 \mathrm{mg} / \mathrm{kg}$ of MPMTE (showing the periportal fatty infiltration) (yellow arrow). (e) Diabetic rat $+400 \mathrm{mg} / \mathrm{kg}$ of MPMTE (portal track showing normal features) (yellow arrow). (f) Diabetic $+100 \mathrm{mg} / \mathrm{kg}$ of Metformin (portal track showing normal features) (yellow arrow).

Observation on MPMTE-treated rats (400mg/kg; p.o.) showed glomeruli and tubules without proteinuria and hemorrhage, suggesting that MPMTE is renoprotective against STZ action. STZ causes diabetic nephropathy, thickening of the glomerular basement membrane, and mesangial expansion, contributing to progressive damage in the glomerular filtration barrier (Alomari et al., 2020; Chen et al., 2017). One of the main diabetic effects is associated with hyperglycemia that is responsible for proximal and distal tubular palsy in the cortex. Secondly, there are individual reaction factors, which are associated with inflammatory processes (Hu et al., 2018; Oyedemi et al., 2011). Diuresis is a common characteristic associated with diabetes which may be due to structural changes observed on the glomerulus (Vallon and Komers, 2011). Interestingly, the liver of diabetic rats treated with $400 \mathrm{mg} / \mathrm{kg}$ of MPMTE had a portal track showing normal features even though STZ caused microvascular vacuolization, focal fat necrosis, and inflammation (Afrin et al., 2015). Hence, this finding indicates that MPMTE could have a hepatoprotective effect against STZ-induced liver damage. This hepatoprotective effect may be due to the presence of polyphenols, stigmasterol, and iridoid compounds that have been proven to protect organs from tissue injury (Nema, Agarwal \& Kashaw, 2011; Viljoen, Mncwangi \& Vermaak, 2012).

\section{CONCLUSION}

MPMTE was potent in reducing blood glucose, total cholesterol, triglycerides, and LDL levels in STZ-induced diabetic rats compared to normoglycemic rats. MPMTE was able to inhibit inflammation, i.e. reduced TNF- $\alpha$ in STZ-induced rats while improving insulin and IGF-1 levels, which is related to the regulation of $\beta$-cells. Furthermore, MPMTE showed a protective effect against STZ-induced organ damage. Thus, MPMTE exhibited great potential for further development in the nutraceutical industries for adjunct treatment of diabetes. Future development of MPMTE should be properly instigated to produce a potential antidiabetic agent as an adjunct therapy in the management of diabetes to improve the quality of life of diabetic patients.

\section{ACKNOWLEDGMENTS}

This study was financially supported by the Ministry of Higher Education, Malaysia, grant number 600- RMI/ST/FRGS 5/3/Fst (14/2009) 
and 600-RMI/FRGS 5/3 (21/2014) and Faculty of Pharmacy, University Teknologi MARA, Malaysia. We would also like to thank everyone who has contributed directly or indirectly to this project.

\section{REFERENCES}

Afrin, R., Arumugam, S., Soetikno, V., Thandavarayan, R.A., Pitchaimani, V., Karuppagounder, V., Sreedhar, R., Harima, M., Suzuki, H., Miyashita, S., Nomoto, M., Suzuki, K., \& Watanabe, K. (2015). Curcumin ameliorates streptozotocin-induced liver damage through modulation of endoplasmic reticulum stressmediated apoptosis in diabetic rats. Free Radical Research; $\quad$ 49(3): 279-289

Aganotovic-Kustrin S., Morton, D.W., Mizaton, H.H., Zakaria, H. (2018). The relationship between major polyphenolic acids and stigmasterol to antioxidant activity in different extracts of Myrmecodia platytyrea. South African Journal of Botany, 115: 94-99.

Aganotovic-Kustrin, S., Morton, DW, Adam, A, Mizaton, HH, Zakaria, H (2017). Highperformance thin-layer chromatographic methods in the evaluation of the antioxidant and anti-hyperglycemic activity of Myrmecodia platytyrea as a promising opportunity in diabetes treatment. Journal of Chromatography A, 1530: 192-196. https://doi.org/10.1016/j.chroma.2017.11. 012.

Alomari, G., Al-Trad, B., Hamdan, S. et al. (2020). Gold nanoparticles attenuate albuminuria by inhibiting podocyte injury in a rat model of diabetic nephropathy. Drug Delivery and Translational Research, 10: 216-226.

Calle, M.C. \& Fernandez. M.L. (2012). Inflammation and type 2 diabetes. Diabetes \& Metabolism, 38(3): 183-191

Chan, J.C.N., Malik, V., \& Jia, W. (2009). Diabetes in Asia: epidemiology, risk factors, and pathophysiology. Journal of the American Medical Association, 301: 2129-2140.

Chen, X., Wu, R., Kong, Y., Yang, Y., Gao, Y., Sun, D., Liu, Q., et al. (2017). Tanshinone II attenuates renal damage in STZ-induced diabetic rats via inhibiting oxidative stress and inflammation. Oncotarget, 8(19): 31915-31922.

Cravotto, G., Boffa, L., Genzini, L. and Garella, D. (2010), Phytotherapeutics: an evaluation of the potential of 1000 plants. Journal of
Clinical Pharmacy and Therapeutics, 35: 1148.

Cree-Green, M., Triolo, Nadeau, K.J. (2013). Etiology of Insulin Resistance in Youth with Type 2 Diabetes. Current Diabetes Reports, 13(1): 81-88.

Dai, Y. L., Zou, Y. X., Liu, F., Li H. Z. (2015). Review: plant polyphenols modulate lipid metabolism and related molecular mechanism. Zhongguo Zhong Yao Za Zhi. 40(21):4136-41.

Ehses, J.A., Lacraz, G., \& Giroix, M.H. (2009). IL-1 antagonism reduces hyperglycemia and tissue inflammation in the type 2 diabetic GK rat. Proceedings of the National Academy of Sciences of the United States of America, 106(33): 13998-14003, 2009.

Feng, S., Dai, Z., Liu, A. B., Huang, J., Narsipur, N., Guo, G., et al. (2018). Intake of stigmasterol and $\beta$-sitosterol alters lipid metabolism and alleviates NAFLD in mice fed a high-fat western-style diet. Biochimica Et Biophysica Acta. Molecular and cell biology of lipids, 1863(10), 1274-1284. https://doi.org/10.1016/j.bbalip.2018.08.0 04

Fox, A., Feng, W. \& Asal, V. (2019). What is driving global obesity trends? Globalization or "modernization"? Global Health 15: 32 https://doi.org/10.1186/s12992-0190457-y

Gandhi, G.R. \& Sasikumar, P. (2012). Antidiabetic effect of Merremia emarginata Burm. F. in streptozotocin induced diabetic rats. Asian Pacific Journal of Tropical Biomedicine, 2(4): 281-286. doi:10.1016/S22211691(12)60023-9

Hasan, M.H., Zin, M.M., Wahab, I.A., Ponto, T., Adam, A. (2018). Myrmecodia platytyrea aqueous tuber extract inhibits pain. Malaysian Journal of Biochemistry and Molecular Biology, 21 (2): 23-27.

Hollenbek, C.B., Chen, Y.D.I., Greenfield, M.S., Lardinois, C.K., \& Reaven, G.M. （1986).

Reduced plasma high density lipoprotein cholesterol concentrations need not increase when hyperglycemia is controlled with insulin in non insulin dependent diabetes mellitus. Journal of Clinical Endocrinology \& Metabolism, 62:605-8.

$\mathrm{Hu}, \mathrm{C}$ and Jia, W. (2018). Diabetes in China: Epidemiology and Genetic Risk Factors and Their Clinical Utility in Personalized 
Medication.

Diabetes, 67(1): 3-

11.https://doi.org/10.2337/dbi17-0013

Hu, R., Xia, C. Q., Butfiloski, E., \& Clare-Salzler, M. (2018). Effect of high glucose on cytokine production by human peripheral blood immune cells and type I interferon signaling in monocytes: Implications for the role of hyperglycemia in the diabetes inflammatory process and host defense against infection. Clinical immunology, 195: 139148.

https://doi.org/10.1016/j.clim.2018.06.00 3

Hugl, S.R., White, M.F., \& Rhodes, C.J. (1998). Insulin-like growth factor I (IGF-I)stimulated pancreatic beta-cell growth is glucose-dependent. activation of insulin Synergistic receptor substrate-mediated signal transduction pathways by glucose and IGF-I in INS-1 cells. Journal of Biological Chemistry, 273: 17771-17779.

Institute for Public Health (2020). National Health and Morbidity Survey (NHMS) 2019: Noncommunicable diseases, healthcare demand, and health literacy-Key Findings

International Diabetes Federation (2020). Retrieved from https://idf.org/aboutdiabetes/what-isdiabetes/facts-figures.html.

Ishihara, K. \& Hirano, T. (2002). IL-6 in autoimmune disease and chronic inflammatory proliferative disease. Cytokine and Growth Factor Reviews, 13(45): 357-368.

Kulkarni, R.N. (2005). New insights into the roles of insulin/IGF-I in the development and maintenance of beta-cell mass. Reviews in Endocrine and Metabolic Disorders, 6 : 199-210.

Liu, Q., Meng, X., Li, Y., Zhao, C. N., Tang, G. Y., \& Li, H. B. (2017). Antibacterial and Antifungal Activities of Spices. International Journal of Molecular Sciences, 18(6), 1283. https://doi.org/10.3390/ijms18061283

Lok, A.F.S.L \& Tan, H.T.W. (2009). Tuberous, epiphytic, rubiaceaous myrmecophytes of Singapore. Nature in Singapore, 2, 231-236

Misra, A., Gopalan, H., Hills, A.P., Soares, M., RezaAlbarran, Ramaiya, K.L. (2019). Diabetes in developing countries. Journal of Diabetes, 11(7): 522-539

Mohamad Haris, N. F., Nik Hasan, M. K., Abdul Wahab, I., Mizaton, H. H., Ponto, T., Adam, A.
(2016). Compounds from the Antioxidant Active Fraction of M. platytyrea. Jurnal Sains Kesihatan Malaysia,14(1): 23-29.

Mohammad, R.M., Afsaneh M.T., Mahmoud, B., \& Mahmoud, R.K. (2016). The research and development on the antioxidants in prevention of diabetic complications. Asian Pacific Journal of Tropical Medicine, 9(9): 825-831

Nema, A. K., Agarwal, A., \& Kashaw, V. (2011). Hepatoprotective activity of Leptadenia reticulata stems against carbon tetrachloride-induced hepatotoxicity in rats. Indian Journal of Pharmacology, 43(3), 254-257. https://doi.org/10.4103/02537613.81507

Oyedemi S, Bradley G, Afolayan A. Antidiabetic activities of aqueous stem bark extract of Strychno shenningsii Gilg in streptozotocinnicotinamide type 2 diabetic rats. Iran Journal of Pharmaceutical Research, 11(1): 221-228.

Oyedemi. S.O., Adewusi, E.A., Aiyegoro, O.A., \& Akinpelu, D.A. (2011). Antidiabetic and haematological effect of aqueous extract of stem bark of Afzelia africana (Smith) on streptozotocin-induced diabetic Wistar rats. Asian Pacific Journal of Tropical Biomedicine, 1(5): 353-358.

Saisho, Y. (2016). Postprandial C-Peptide to Glucose Ratio as a Marker of $\beta$ Cell Function: Implication for the Management of Type 2 Diabetes. International Journal of Molecular Sciences, 17(5), 744. doi.org/10.3390/ijms17050744

Samatha, P., Venkateswarlu, M., \& Siva, P.V. (2012). Lipid profile levels in type 2 diabetes mellitus from the tribal population of Adilabad in Andhra Pradesh, India. Journal of Clinical and Diagnostic Research, 6(4):590-592.

Shaw, J.E., Sicree, R.A., \& Zimmet, P.Z. (2010). Global estimates of the prevalence of diabetes for 2010 and 2030. Diabetes Research and Clinical Practice, 87: 4-14.

Shi, J., Hu, H., Zheng, X. Liang, Z, Wang, Y.T., Ung, C.O.L. (2019). An evaluation of randomized controlled trials on nutraceuticals containing traditional Chinese medicines for diabetes management: a systematic review. Chinese Medecine, 14: 54.doi: 10.1186/s13020-019-0276-3

Vallon, V., \& Komers, R. (2011). Pathophysiology of the diabetic kidney. Comprehensive 
Physiology, 1(3):

1175-1232. https://doi.org/10.1002/cphy.c100049

Vázquez-Fresno, R., Rosana, A.R.R., Sajed, T. Onookome-Okome, T., Wishart, N. A., Wishart, D. S. (2019). Herbs and SpicesBiomarkers of Intake Based on Human Intervention Studies - A Systematic Review. Genes \& Nutrition. 14: 18. https://doi.org/10.1186/s12263-0190636-8

Viljoen, A., Mncwangi, N., \& Vermaak, I. (2012). Anti-inflammatory iridoids of botanical origin. Current Medicinal Chemistry, 19(14): 2104-2127. https://doi.org/10.2174/09298671280022 $\underline{9005}$

Wellen, K.E., \& Hotamisligil, G.S. (2005). Inflammation, stress, and diabetes. Journal of Clinical Investigation, 115(5): 1111-1119.

Witztum J.I., Fisher, M., Pietro, T., Steintracher, U.P., \& Iiam, R.I. (1982). Nonenzymatic glucosylation of high-density lipoprotein accelerates its catabolism in guinea pigs. Diabetes. 31:1029-32

Zimmet, P.Z., Magliano, D.J., Herman, W.H. and Shaw, J.E. (2014). Diabetes: A 21st century challenge. Lancet Diabetes Endocrinology, 2, 56-64. 